Юрий Веселов, Ольга Таранова, Цзюнькай Цзинь

\title{
ГОРЬКИЙ ХЛЕБ СТАРОСТИ? СОЦИАЛЬНЫЕ ПРАКТИКИ ПИТАНИЯ ПОЖИЛЫХ ЛЮДЕЙ
}

Одна из важных задач социологии питания - исследование социальной дифференциации и повседневных практик потребления продовольствия различными социальными группами населения. В статье рассматриваются вопросы питания пожилых людей. На основе эмпирического исследования «Еда и мы» и анализа статистики, мы показываем, как обстоит дело с питанием пожилых людей. Вопреки устоявшемуся стереотипу - старики питаются очень плохо, мы утверждаем, что в группе пожилых людей есть существенные различия. Базовым фактором, определяющим такую модель потребления, является образование, формирующее рациональный и систематический подход к потребляемой пище. В первой части статьи рассматривается предмет социологии питания и ее теоретические основания. Мы утверждаем, что процессы потребления еды социально структурированы и институциализированы. Вкус к еде пожилых людей определен их габитусом, который формировался еще в советское время тотального дефицита продуктов питания (отсюда склонность пожилых людей делать запасы). Он зависит как от экономических возможностей, так и от обладания культурным капиталом. Еда - это система коммуникации, она всегда обозначает определенную социальную ситуацию: разговоры пожилых людей вращаются вокруг рынков, магазинов, цен на продовольствие, акций супермаркетов, возможностей приготовления

Юрий Витальевич Веселов - д.с.н., профессор, заведующий кафедрой экономической социологии, факультет социологии, Санкт-Петербургский государственный университет, Санкт-Петербург, Россия. Электронная почта: yurivitalievichveselov@yahoo.com

Ольга Александровна Таранова - ассистент кафедры экономической социологии, факультет социологии, Санкт-Петербургский государственный университет, Санкт-Петербург, Россия. Электронная почта: o.a.taranova@gmail.com

Цзюнькай Цзинь - аспирант кафедры экономической социологии, факультет социологии, Санкт-Петербургский государственный университет, Санкт-Петербург, Россия. Электронная почта: j530519513@126.com 
различных блюд. Так еда тематизируется и наполняется смыслом. Затем мы рассматриваем структуру и режимы питания пожилых людей (на основе статистических данных Росстата и Петростата); основная проблема - несбалансированная диета пожилых людей, перекос в сторону дешевой углеводной пищи, при дефиците белков и полезных жиров. Мы исследуем социальные различия в питании пожилых людей; еду вне дома как фактор их социализации; изучаем взаимосвязь здоровья и питания, а также социально-психологическое отношение к еде. В заключении подводятся итоги и даются практические рекомендации по созданию системы здорового питания пожилых людей.

Ключевые слова: пожилые люди, еда, здоровье, социология питания

DOI: $10.17323 / 727-0634-2018-16-1-81-94$

\section{Изучение проблем питания пожилых}

Цель нашего исследования - изучение повседневных практик питания пожилых. Мы формулируем наше исследование в рамках социологии питания. Почему социология должна изучать питание? Во-первых, питание - это социальная деятельность. Процессы питания социально структурированы и нормированы. Во-вторых, питание формирует и дифференцирует социальные группы, то есть через питание одна группа отличает себя от другой (богатые от бедных, пожилые от молодых). В-третьих, процесс питания является типичным социальным действием, так, как определял его Макс Вебер (Вебер 1990: 602): еда наделена определенным особым смыслом, а ее потребление часто ориентируется не только на самих себя, но и на других.

Система питания (или ее отсутствие) является одним из факторов, оказывающих влияние на здоровье людей всех возрастов, но для пожилых людей такое утверждение еще более значимо. По данным ВО3, в 2015 г. в мире из 56,4 млн случаев смерти около четверти, 15 млн смертей, вызваны ишемической болезнью сердца и инсультом, болезнями питания и обмена веществ (ВО3 2017). Часто пожилые люди обращают внимание на правильное питание только тогда, когда в состоянии здоровья уже произошли необратимые изменения. Можно было бы предположить, что проблемы питания пожилых (несбалансированное питание и нездоровые привычки) это следствие недостаточного материального обеспечения. Действительно, существует связь между доходами и структурой питания (Колосницына, Бердникова 2009: 75). Исследования показывают, что чем ниже доход, тем больше покупается дешевой углеводной пищи (меньше дорогого мяса и больше дешевого картофеля или макарон). Но вот парадокс - обеспеченные слои населения питаются не лучше остальных, а просто больше по объему (Веселов, Цзинь 2017:253). Здоровое питание не приобретается 
вместе с ростом дохода, для этого надо формировать культуру, необходимо просвещение и образование в области правильного питания.

Социология питания изучает повседневные практики питания, структуру и режимы питания, а также культуру питания. Отдельно стоит оговорить различие в понятиях «пожилой человек» и «пенсионер». Пожилой возраст по классификации ВОЗ попадает в диапазон от 60 до 75 лет, от 75 до 90 лет - представители старшего возраста, старше 90 лет - долгожители. Однако современный взгляд на старение и границы пожилого возраста определяются не просто цифрой, тенденция последних десятилетий - постепенное движение в сторону более позднего старения. «Пожилой» возраст в России в официальных документах и статистических данных от Росстата начинается уже с 55 лет для женщин и 60 лет для мужчин, то есть с официальным наступлением пенсионного возраста. В силу отсутствия стратифицированных по возрасту статистических данных мы вынуждены рассматривать питание «пожилого человека» и «пенсионера» условно как тождественное, хотя это и не совсем верно.

\section{Теоретические основания}

Большой вклад в социологию питания внесли британские и французские антропологи (Richards 1995; Lévi-Strauss 2008). Изучая социальную организацию ранних обществ, они заметили, что процессы питания с самого начала человеческой истории строго нормированы, ритуализированы и институциализированы. Мы используем это положение в теоретическом осмыслении питания пожилых людей: определенный тип и практики питания, свойственные пожилым, создают соответствующие социальные границы группы. Пожилые люди идентифицируют себя со своей социальной группой по признаку выбора продуктов (весьма значимы для них сохранившиеся с советского времени предпочтения вкуса); по технологиям покупки, приготовления и хранения продуктов (например, консервирование продуктов); по критерию рационализации выбора продуктов (минимизация затрат при возможном снижении качества продуктов). Особенно это заметно во время общей трапезы, когда образуется единое социальное пространство питания, где люди чувствуют себя единой социальной общностью.

Во французской традиции социологии питания нельзя не отметить работы Ролана Барта. Он доказывает, что еда - это система коммуникации (Barthes 2008:21). Для пожилых людей это утверждение особенно актуально. Мы заметили, что суждения пожилых вращаются вокруг тем еды, продуктов, цен, рынков, приготовления, заготовок, обедов, завтраков и ужинов. Так создается «дискурс еды», семиотически наполненный и соответствующим образом структурированный. Еда наполняется смыслами, мифологизируется и служит обозначением социальной ситуации (семейные 
обеды, например), способствуя воспроизводству социальных отношений (в данном случае родственных).

Для нашей темы важны исследования в рамках структуралистского конструктивизма, главным представителем которого является Пьер Бурдье. Он показывает, как вкус связан с габитусом. Каждый социальный класс формирует свой собственный вкус - это может быть вкус к роскоши (как у богатых), так и вкус к необходимому (Бурдье 2004). У пожилых людей с возрастом формируется особый вкус к еде, некоторые продукты исключаются, другие наоборот включаются в рацион, но важно, что пожилые формируют и поддерживают собственное пространство вкуса (которое, конечно, зависит и от других социальных факторов). Часто оно наполнено и утраченными вкусами далекого прошлого (так называемый «тот самый вкус», из детства или юности). Так что пространство вкуса не только сиюминутное, но и исторически протяженное. Что важно для пожилых, пищевая ностальгия становится частью их самоидентификации. В современном обществе именно посредством вкуса высший класс отличает себя от низшего, одна социальная группа от другой, говорит Бурдье. Пожилые не стремятся копировать чужие вкусы, но в то же время это не означает, что они довольны тем, как питаются. Наоборот, они чаще неудовлетворенны качеством своего питания (что подтверждается нашими эмпирическими данными), вспоминая прошлое, предаваясь ностальгии, они безуспешно пытаются найти «потерянный рай» пищевых удовольствий.

Для анализа питания важны и другие факторы. Бурдье настаивает на важности культурного капитала (Бурдье 2004), и именно этот фактор мы берем для построения дифференциации в группе пожилых. Наши исследования подтверждают, что качество питания пожилых зависит во многом не от дохода, а от образования. Именно образование является тем маркером, который делит эту группу на тех, кто питается правильно и неправильно (Веселов 2015: 95-104; 2014: 168-199; Зарубина, Кравченко 2017; Зарубина 2014).

\section{Потребление продуктов питания пожилыми людьми и социальная дифференциация}

Что едят пожилые люди в России? Росстат и Петростат публикуют с 2013 г. пищевые рационы жителей. Это не сплошные, а выборочные исследования, они основываются на обследовании домохозяйств (в России опрошено 45 тыс. домохозяйств, в Санкт-Петербурге - 930). Сравним потребление основных продуктов питания пожилыми людьми в РФ с потреблением людьми в трудоспособном возрасте. Росстат считает потребление по разным возрастным группам, мы возьмем только возрастную группу старше трудоспособного возраста отдельно для мужчин и женщин (Росстат 2016). 


\section{Таблица 1}

Среднедушевое потребление продуктов питания, килограмм, значение показателя за год, Российская Федерация, 2013

\begin{tabular}{|c|c|c|c|c|}
\hline Продукты & 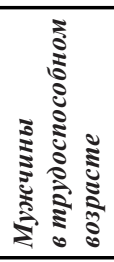 & 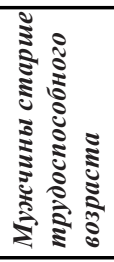 & 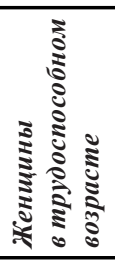 & 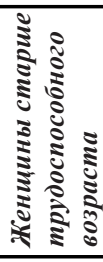 \\
\hline Хлебные продукты & 111,7 & 105,3 & 72,9 & 83,2 \\
\hline Мясо и мясопродукты & 126,6 & 96,1 & 77,5 & 63,2 \\
\hline Рыба и рыбопродукты & 27,1 & 29,2 & 20,0 & 21,5 \\
\hline $\begin{array}{l}\text { Молоко и молочные } \\
\text { продукты, литр }\end{array}$ & 314,7 & 316,8 & 276,5 & 277,1 \\
\hline Яйца, штук & 311 & 264 & 177 & 161 \\
\hline $\begin{array}{l}\text { Масло растительное и другие } \\
\text { жиры }\end{array}$ & 13,6 & 10,2 & 10,1 & 7,9 \\
\hline Фрукты и ягоды & 72,2 & 64,5 & 85,9 & 76,4 \\
\hline Овощи и бахчевые & 119,0 & 109,5 & 100,7 & 95,3 \\
\hline Картофель & 88,9 & 78,7 & 59,5 & 58,1 \\
\hline Caxap & 31,7 & 27,1 & 24,1 & 22,0 \\
\hline
\end{tabular}

Источник: данные Росстата (Росстат 2016)

Как видно из Таблицы 1, мужчины старше трудоспособного возраста потребляют в сравнении с мужчинами трудоспособного возраста существенно меньше мяса и яиц, немного меньше фруктов и овощей, но зато также меньше картофеля и сахара. Женщины старше трудоспособного возраста увеличивают потребление хлеба. При этом статистики отмечают улучшение режимов питания у пожилых людей - увеличивается процент людей, принимающих пищу несколько раз в день, а не один раз в день. Сбалансирована ли структура питания пожилых людей? Если мы рассмотрим структуру потребления пенсионеров, то на одного жителя приходится: 75 г белка в день (в т. ч. животного 51 г), 103 г жиров, 304 г углеводов и 2466 ккал в сутки (для пенсионеров рассчитанный Росстатом средний уровень потребляемых калорий меньше - 2225 ккал). Баланс 
получаемой энергии выглядит так: 31 \% энергии получается за счет хлеба, $35 \%$ - за счет мяса и молока, $11 \%$ - за счет сахара (Петростат 2015:26). Оптимальная пропорция белков-жиров-углеводов по методике Всемирной организации здравоохранения составляет $18 \%-25 \%-57 \%$. В СанктПетербурге в среднем получается $15,5 \%-21,3 \%-63 \%$. Это значит, что петербургский житель в среднем недополучает белка и полезных жиров (масла растительного петербуржцы, потребляют на 2 кг в год меньше, чем средний россиянин). Пожилые люди как в России, так и в Петербурге, потребляют гораздо меньше белков и жиров. Например, мужчины в пожилом возрасте потребляют на 20 кг в год меньше мяса и на 3,4 кг меньше растительного масла; женщины - меньше мяса на 14,3 кг и масла на 2,2 кг. Итак, потребление продуктов питания пожилыми людьми с точки зрения медицинских норм не сбалансировано, наблюдается перекос в пользу углеводов за счет сокращения белков (в основном, мяса) и полезных жиров (растительного масла).

В Петербурге на 2016 г.- 1 млн 447 тыс. пенсионеров; средний размер пенсии в 2016 г.- 13739 руб./мес. Не могут позволить себе еду с мясом, рыбой или птицей через день 16,5\% петербуржцев; фруктов через день не в состоянии купить $12,2 \%$. Для пенсионеров эта доля существенно выше - 52 и $43 \%$ соответственно. Мы можем с уверенностью утверждать, что пожилые как возрастная группа в обществе в отношении возможностей питания наиболее депривирована. Петростат рассчитывает и субъективные показатели достаточности питания для пенсионеров: на вопрос «3a noследние 3 мес. часто бывает так, что недостаточно еды?» ни один пенсионер в Петербурге не ответил утвердительно; но вот на вопрос «Иногда былает недостаточно едbl?» 10,2\% ответили утвердительно. Таким образом, в среднем для людей пожилого возраста еды практически всегда достаточно. Тогда в чем ощущают проблему питания пожилые люди? 54,5 \% отвечают, что «достаточно едbl, но не той, которую хотелось бы есть». Для других групп населения этот показатель от 27 до 33 \% (Петростат 2013: 1). Значит, пожилые люди часто едят не то, что предпочитают: 1,6\% пенсионеров сообщает о том, что не было поступления (покупки) овощей, зелень или салат не покупали $5,7 \%$, консервы - 19\%, фрукты - 2,2\%, соки - $28 \%$, мясо $6,3 \%$, колбасу и сосиски - 10,1\%, рыбу $-4,8 \%$ и только сливочное масло покупают все пенсионеры. Тревожной является ситуация, что существует определенный слой внутри группы пожилых людей, от 5 \% до 7\%, которые не могут позволить и вообще не едят мяса или рыбы, зелени и фруктов. Для этой группы необходима адресная продовольственная помощь. Так что же едят пожилые люди, из чего состоит их обед? Каждый день или несколько раз в неделю 97,5\% людей старше трудоспособного возраста едят хлеб, 79,4\% - каши и макароны, 75,5\% - мясо, 29,9\% - рыбу (Росстат 2016: 19). А вот овощи и фрукты каждый день или несколько раз в неделю могут себе позволить 53,8\% и $46 \%$ пожилых соответственно. 


\section{Гастрономические предпочтения и отношение к правильному питанию у пожилых}

Для пожилых людей их мир «начинается с кухни». Для этой социальной группы питание, продукты, цены на продовольствие, завтрак, обед и ужин находятся в центре внимания. Что готовят себе пенсионеры? Такие данные невозможно получить через официальную статистику, поэтому мы провели собственное исследование «Еда и мы: социальные практики питания петербуржцев» (2017 г.) для выяснения гастрономических предпочтений пожилых людей в городе (в нашем исследовании пожилые - это мужчины и женщины после 60 лет). В телефонном опросе (система $C A T I$ ) участвовало 1056 чел., выборка репрезентативна для Санкт-Петербурга по основным социальнодемографическим параметрам. Исследование проводилось центром Научного парка СПбГУ «Социологические и интернет исследования.

Предпочтения на завтрак. Самый популярный ответ среди всех респондентов, независимо от возраста,- это каша. Так ответили от 45 до $56 \%$ жителей Петербурга в разных возрастных категориях, но люди пожилого возраста предпочитают такой завтрак в большей степени, чем молодежь. Для этой социальной группы предпочтительны следующие варианты завтрака: бутерброды (37\%), кисломолочные продукты (23\%), нарезка (колбаса, ветчина, рыба, сыр - 17\%), чай, кофе и прочие напитки (77\%). Также они употребляют больше блинов, оладий, сырников, т.е. блюд, требующих весомых временных затрат на приготовление. Предпочтения на обед. Для пожилых обед - это всегда горячее блюдо; суп - $80 \%$; пожилые выбирают его на $20 \%$ больше, чем молодежь; суп едят обычно с хлебом; второе - это мясо или птица - $31 \%$; рыба - $21 \%$; на гарнир картофель - $22 \%$ или крупы - $17 \%$; макароны пожилые предпочитают меньше всех остальных возрастных групп (13\%); овощи одинаково популярны среди всех возрастных групп (в среднем $21 \%$ ), блины, оладьи и блюда из яиц на обед выбирают исключительно пожилые (2\%). Не обедают $3 \%$ пожилых. Предпочтения на ужин: мясо птицы $18 \%$; картофель $21 \%$; в 4,5 раза чаще молодежи предпочитают на ужин бутерброды $(13,3 \%)$, в 2 раза чаще дополняют ужин сладким (3,6\%), едят в 3 раза больше каш (12\%). Также по мере увеличения возраста возрастает популярность кисломолочных продуктов на ужин (с $17 \%$ до 30\%), нарезки (в 6 раз чаще). Отношение к алкоголю среди пожилых: $28 \%$ утверждают, что вообе не употребляют алкоголь; на вопрос «Что вы пили вчера?» 57\% ответили, что не пили никаких алкогольных напитков, $9 \%$ пили водку, $4 \%$ - вино, 2,5\% - пиво.

В качестве промежуточных выводов отметим, что, во-первых, у пожилых людей слишком велика доля бутербродов и на завтрак, и на обед (бутерброды включают либо сливочное масло или/и колбасу, ветчину или сыр). Следовательно, слишком большая доля продуктов с высокой степенью жирности. Во-вторых, как на обед, так и на ужин велика доля картофеля 
как основного гарнира. В-третьих, совершенно оправдано на обед и на ужин у пожилых снижается доля потребления мяса, но она не компенсируется возрастанием потребления рыбы, которая менее калорийна и легче усваивается. Наблюдается устойчивый спад уровня удовлетворенности качеством и разнообразием питания по мере увеличения возраста (разница между молодёжью и пожилыми составляет $16 \%$ ). Среди респондентов, заявивших, что их совершенно не устраивает содержательная составляющая питания, пожилые встречаются в 5 раз чаще. В нашем исследовании мы спрашивали респондентов, блюда какой кухни они предпочитают. Интерес к русской и советской кухне выявлен в большей степени среди пожилых людей (60\%).

Выявилась серьезная проблема для пожилых в области питания как социализации - 72\% пожилых петербуржцев не посещает мест общественного питания, а остальные бывают в кафе один или несколько раз в месяц (54\%), а в ресторане несколько раз в год (43\%). Соответственно, у пожилых людей сужаются возможности социализации (хотя походы в кафе - не единственная возможность социализации, пожилые любят ходить в гости и приглашать к себе гостей). Но любой «выход в свет»- это поддержание способности к коммуникации (а, следовательно, мыслительной деятельности), сохранение своей физической формы, событие, куда ходят либо с семьей (43\%), либо с друзьями (39\%). Сравнивая пожилых в России и Европе, можно заметить, что продолжительность жизни напрямую зависит от сохранения функции социализации, в том числе и посредством социальных практик питания. Европейские пенсионеры так же экономны в «выходе в свет» (достаточно заказать чашку кофе), но сохраняя эту традицию, они поддерживают себя в форме: делают причёски, одеваются в праздничную одежду (Blaakilde, Nilsson 2014).

Итак, мы можем сделать следующие выводы относительно правильного питания пожилых. Во-первых, они больше, чем другие возрастные категории, понимают важность здорового питания, отмечая существенность снижения содержания соли и повышения содержания клетчатки в пище, а также значимость рациона питания для поддержания себя в хорошей форме. Во-вторых, пожилые в большей степени, чем другие возрастные категории, придерживаются правил здорового питания: чаще предпочитая нежирную пищу, потребляя молоко низкой жирности, используя низкокалорийную заправку к салатам, исключая сахар (особенно женщины, 26,5%), а 65-68\% следуют хотя бы одному диетарному предписанию.

Эти данные Росстата подтверждаются и нашим исследованием. В целом, большинство жителей Санкт-Петербурга (от 70 до 81 \%) не придерживаются особой системы питания, независимо от возраста. Однако количество респондентов пожилого возраста, придерживающихся лечебного питания $(12 \%)$, в 4 раза больше, чем среди молодёжи. Лица старше 60 лет чаще остальных групп держатся низкоуглеводной и бессолевой диеты (7 и $4 \%$ соответственно). Тогда почему так высока доля избыточного веса у пожилых 
людей, если они придерживаются правил здорового питания? Во-первых, лишний вес в пожилом возрасте часто является следствием нарушения правил питания в среднем возрасте. Во-вторых, приведенные выше данные в отношении правильного питания являются относительными, но в абсолютных цифрах эти показатели не так велики. Например, выбор здорового рациона для похудения или поддержания нормы веса считают совсем неважным 30\% россиян и 32,2\% пожилых людей (Росстат 2016:55-66). Необходимо отметить проблему, заключающуюся в пассивности и стереотипах мышления: почти половина респондентов в опросе Росстата считают, что «некоторые люди рождены быть толстыми, а некоторые - худыми, и человек мало что может сделать, чтобы на это повлиять». В большей степени так считают пожилые женщины (61,8\%). При этом они считают, что их рацион питания сбалансирован и нет необходимости что-либо в нем менять $(68,2 \%)$ (Росстат 2016: 55-66, 71).

\section{Питание и здоровье}

Пожилые люди в российском обществе стигматизируются как «больные и бедные», широко распространено мнение, что они питаются очень плохо и из-за этого болеют. Как на самом деле связано питание и здоровье? Сегодня медицинская наука однозначно связывает избыточный вес и ожирение с болезнями (BO3 2016; Abarca-Gomez 2017). Стройность и худоба стали признаками социального отличия в мире изобилия еды, быть стройным модно и престижно. Однако этот модный образец не относится к миру пожилых людей. Они в большей степени, чем молодые люди, страдают от болезней избыточного веса и ожирения. В среднем по РФ 20,4\% мужчин считают, что их вес избыточный (в Санкт-Петербурге - 21,6\%, в Москве - 28,3\%); среди женщин - 38,9\% (в Санкт-Петербурге - 40,3\%, в Москве - 40,7\%) (Росстат 2016: 140-144). Но это субъективные оценки избыточного веса.

По данным НИИ питания Академии медицинских наук РФ (Башарова 2016), каждый четвертый россиянин страдает ожирением (Россия занимает 30-е место в мире, в лидерах - арабские страны, США на 11 месте). Избыточный вес имеют 50\% мужчин и $60 \%$ женщин старше 30 лет. По данным исследования НИУ ВШЭ, в Санкт-Петербурге доля мужчин, страдающих ожирением, составляет $13,8 \%$, женщин - 21,3\%; в Москве - $20 \%$ и $30 \%$ соответственно (Козырева и др. 2014: 143, 146). Как видно из представленных данных, субъективные и объективные оценки избыточного веса различаются. Доля людей с ожирением мало зависит от доходов (в социальном слое самых бедных их $19 \%$, а среди самых богатых - 23,4\%), тогда как образование существенно влияет на индекс массы тела: лучшие показатели этого индекса наблюдаются у лиц с высшим образованием (Гремченко, Рощина 2016: 145, 146).

Для пожилых людей влияние питания на здоровье очевидно возрастает. Данные Росстата показывают, что в возрасте 60-69 лет 65,5\% имеют 
повышенное артериальное давление; диабет или повышенный сахар в крови - 14,1\%; повышенный уровень холестерина $-21,2 \%$; заболевания желудка - 27,5\% (Росстат 2016: 50). Также интересно сравнить данные о заболеваниях в зависимости от избыточной массы тела человека и ожирения. Для страдающих ожирением существует прямая связь с такими болезнями, как повышенное артериальное давление, диабет, высокий уровень холестерина, инсульт и переломы костей. Примечательно, что современные американские исследования физической активности по странам (на основе анализа Big Data, данных смартфонов о количестве пройденных шагов за день, согласно исследованию Стэнфордского университета) показывают, что нет строгой зависимости физической активности и уровня ожирения (Althoff et al. 2017). Россияне являются одними из самых подвижных людей в мире (в среднем 5969 шагов в день при среднем количестве шагов в мире 4961), но при этом имеют высокий уровень ожирения.

Мы предполагали, что образование пожилых является одним из важных факторов обеспечения правильного питания, а, следовательно,- хорошего здоровья. Эта гипотеза была проверена на статистических данных Росстата. Люди с высшим образованием предпочитают нежирную мясную пищу, едят фрукты вместо сладких десертов, в большей степени не употребляют сахар (20\% лиц с высшим образованием и только $13 \%$ лиц с начальным) и принимают витамины (Росстат 2016: 54-55, 60). Наша гипотеза подтверждается в отношении пожилых женщин, тогда как пожилые мужчины, вне зависимости от наличия высшего образования, меньше внимания обращают на правильное питание и, следовательно, на свое здоровье. В ходе исследования удивительным оказался тот факт, что доля заболеваний, в теории связанных с избыточным весом, прямо не зависит от доли людей с избыточным весом. В Москве доля людей с ожирением выше, чем в СанктПетербурге, а в Петербурге выше, чем в Москве, доля заболеваний, связанных с избыточным весом. Например, повышенное артериальное давление имеют в Москве 21,9\%, а в Санкт-Петербурге - 26\%, диабет - 4 и 5,5\% соответственно, повышенный уровень холестерина - 6,7 и 8,9\%, пищевую аллергию - 7 и $11 \%$ (Росстат 2016: 144-147).

Таким образом, связь между здоровьем, избыточным весом и питанием не непосредственна, и следует включать в анализ иные факторы, влияющие на заболевания - климат, уровень жизни, социальную обстановку (например, расслоение общества). Обозначенная гипотеза, без сомнения, нуждается в дальнейшем подтверждении расширенными эмпирическими данными.

\section{Заключение}

В статье рассмотрены практики питания пожилых, в основном на примере Санкт-Петербурга. В заглавии «Горький хлеб старости» стоит знак вопроса-мы хотели показать, что вопреки устоявшемуся стереотипу пожилые 
люди питаются не так уж плохо. По крайней мере, вопрос голода или недоедания не стоит. Гораздо более значимы проблемы выбора продуктов питания. По многим критериям пожилые люди питаются правильнее, чем другие возрастные группы в России. Основные проблемы, связанные с питанием пожилых, сводятся к следующему: во-первых, питание не полностью сбалансировано. Во-вторых, в структуре потребления присутствует много простых углеводов, замещающих белки, что, вместе с возрастными изменениями в обмене веществ, приводит к избыточному весу и в определенной степени способствуют развитию заболеваний (повышенное артериальное давление, высокий уровень холестерина, заболевания желудочно-кишечного тракта). В-третьих, не столько отсутствие средств у пожилых людей, сколько стереотипные практики питания и отсутствие культуры правильного питания не дают возможности разнообразить диету.

Что можно порекомендовать в области совершенствования питания пожилых людей? Во-первых, развивать рациональный, научно обоснованный подход к питанию, для этого важно консультирование и программы просвещения в области здорового и правильного питания. Во-вторых, направить усилия на формирование гастрономической культуры пожилых, своеобразного типа культурного капитала; приобщать к правилам хорошей кухни, не бояться использовать различные, в том числе новые, продукты питания (и не обязательно дорогие). В-третьих, изменение структуры питания от потребления т.н. быстрых углеводов в сторону рыбы и морепродуктов. В-четвертых, внутри группы пожилых есть определенный слой, от 5\% до 7\%, не употребляющих мяса или рыбы, зелени и фруктов. Для этой группы необходима адресная государственная продовольственная помощь.

\section{Выражение благодарности}

Статья подготовлена при финансовой поддержке РФФИ, грант 17-03-00631 «Повседневные практики питания и общественное здоровье населения (на примере Санкт-Петербурга и Ленинградской области)», с использованием оборудования ресурсного центра Научного парка СПбГУ «Социологические и интернет исследования» в 2017 г.

\section{Список источников}

Башарова С. (2016) Ожирением страдает каждый пятый россиянин. Доступно по ссылке: https://iz.ru/news/601514 (дата обращения: 1 октября 2017).

Бурдье П. (2004) Различение: сочиальная критика суждения. Западная экономическая соииология: Хрестоматия современной классики. В. В. Радаев (сост. и науч. ред.). М.: РОССПЭН: 537-565.

Вебер М. (1990) Избранные произведения. М.: Прогресс.

Веселов Ю.В. (2015) Повседневные практики питания. Социологические исследования, (1): $95-104$. 
Веселов Ю.В. (2014) Социология питания: теоретические основания. Проблемы теоретической сочиологии, (10): 168-199.

Веселов Ю. В., Цзинь Ц. (2017) Санкт-Петербург в зеркале сравнительной социологии питания. В: Экономическая культура мегаполиса. Альманах Центра исследований экономической культуры. СПб: Институт Гайдара:248-268.

BO3 (2017) 10 ведущих причин смерти в мире. Доступно по ссылке: http://www.who. int/mediacentre/factsheets/fs310/ru/ (дата обращения: 1 октября 2017).

ВО3 (2016) Неполноченное питание в иеетре внимания. Доступно по ссылке: http:// www.who.int/nutrition/pressrelease-FAOWHO-symposium-malnutrition/ru/ (дата обращения: 1 октября 2017).

Гремченко Е. П., Рощина Я.М. (2016) Факторы склонности к здоровому образу жизни. Вестник Российского мониторинга экономического положения и здоровья населения НИУ ВШЭ (RLMS-HSE), (6): 118-163.

Зарубина Н.Н. (2014) Практики питания как маркер и фактор социального неравенства в России. Историческая психология и сочиология истории, (2):46-62.

Зарубина Н.Н., Кравченко С. А. (ред.) (2017) Социология питания: традиции и трансформации. М.: МГИМО.

Козырева П. М., Сафронова А.М., Старовойтов М.Л. (2014) Анализ фактического питания и пищевого статуса различных групп населения. Вестник Российского мониторинга экономического положения и здоровья населения НИУ ВШЭ (RLMSHSE), (4): 131-166.

Колосницына М.Г., Бердникова А.Н. (2009) Избыточный вес: сколько это стоит и что с этим делать? Прикладная эконометрика, 3 (15): 72-92.

Петростат (2015) Потребление продуктов питания в домашних хозяйствах СанктПетербурга. Доступно по ссылке: http://petrostat.gks.ru/wps/wcm/connect/rosstat_ts/ petrostat/resources/0fd259004eb7121ebacefb0d534aab22/15000516-2015.pdf (дата обращения: 1 октября 2017).

Петростат (2013) Итоги выборочного наблюдения рациона питания населения в 2013 году. Доступно по ссылке: http://petrostat.gks.ru/wps/wcm/connect/rosstat_ts/petrostat/ resources/627571804eaa60daa971fb0d534aab22.pdf (дата обращения: 1 октября 2017).

Росстат (2016) Рацион питания населения 2013. Доступно по ссылке: http://www.gks. ru/free_doc/new_site/population/urov/razion.pdf (дата обращения: 1 октября 2017).

Abarca-Gómez L. et al. (2017) Worldwide Trends in Body-Mass Index, Underweight, Overweight, and Obesity from 1975 to 2016: A Pooled Analysis of 2416 Population-Based Measurement Studies in 128.9 Million Children, Adolescents, and Adults. The Lancet. Available at: http://www.thelancet.com/journals/lancet/article/PIIS0140-6736(17)32129-3 (accessed 1 October 2017).

Althoff T., Sosic R., Hicks J., King A., Delp S., Leskovc J. (2017) Large-Scale Physical Activity Data Reveal Worldwide Activity Inequality. Nature. Available at: http://www.nature. com/nature/journal/vaop/ncurrent/full/nature23018.html (accessed 1 October 2017).

Barthes R. (2008) Toward a Psychosociology of Contemporary Food Consumption. In: C. Counihan, P. Van Esterik (eds.) Food and Culture: A Reader. New York: Routledge:28-35.

Blaakilde A. L., Nilsson G. (eds.) (2014) Nordic Seniors on the Move: Mobility and Migration in Later Life. Lund: Lund University.

Lévi-Strauss C. (2008) The Culinary Triangle. In: C. Counihan, P. Van Esterik (eds.) Food and Culture: A Reader. New York: Routledge: 36-43.

Richards A. (1995) Land, Labour, and Diet in Northern Rhodesia: An Economic Study of the Bemba Tribe. Munster: LIT Verlag. 
Yuri Veselov, Olga Taranova, Junkai Jin

\title{
THE BITTER BREAD OF OLD AGE? SOCIAL PRACTICES OF NUTRITION AMONG ELDERLY PEOPLE
}

\begin{abstract}
One of the most important tasks facing the sociology of food is studying social differentiation in eating and the nutrition practices of various social groups. This article considers the nutrition practices of elderly people and is based on an empirical study in St. Petersburg entitled 'Food and Us'. This included both in-depth interviews and telephone interviews held over 2016 and 2017, as well as an analysis of federal and regional statistics. What is revealed is the that, contrary to popular notions that elderly people eat very poorly, there are significant differences in nutrition among elderly groups. The basic factor that determines the nutrition model is higher education, which forms a rational and systematic approach to eating. In the first part of the article, the subject of sociology of nutrition and its theoretical background are examined. Then we consider how the nutrition of the elderly is structured by examining Rosstat and Petrostat statistics on diet regimes, social differences in nutrition, and eating out for elderly people. We study the relationship between health and nutrition, as well as the attitudes towards food based on the data of our own empirical research. In conclusion, we analyze the nutrition problems of the elderly and give some recommendations concerning the creation of healthy diets for the elderly.
\end{abstract}

Key words: elderly people, food, health, obesity, disease, sociology of food DOI: $10.17323 / 727-0634-2018-16-1-81-94$

\section{References}

Abarca-Gómez L. et al. (2017) Worldwide Trends in Body-mass Index, Underweight, Overweight, and Obesity from 1975 to 2016: A Pooled Analysis of 2416 Population-based Measurement Studies in 128.9 million Children, Adolescents, and Adults. The Lancet. Available at: http://www.thelancet.com/journals/lancet/article/PIIS0140-6736(17)32129-3 (accessed 1 October 2017).

Althoff T., Sosic R., Hicks J., King A., Delp S., Leskovc J. (2017) Large-scale Physical Activity Data Reveal Worldwide Activity Inequality. Nature. Available at: http://www.nature.com/ nature/journal/vaop/ncurrent/full/nature23018.html (accessed 01 October 2017).

Barthes R. (2008) Toward a Psychosociology of Contemporary Food Consumption. C. Counihan, P. Van Esterik (eds.) Food and Culture: A Reader. New York: Routledge:28-35.

Basharova S. (2016) Ozhireniem stradaet kazhdyy pyatyy rossiyanin [Every Fifth Russian Suffers from Obesity]. Available at: https://iz.ru/news/601514 (accessed 01 October 2017).

Yuri Veselov - Ph.D (Sociology), Professor, Head of the Department of Economic Sociology, Faculty of sociology, Saint-Petersburg State University, Saint Petersburg, Russian Federation. Email: yurivitalievichveselov@yahoo.com

Olga Taranova - Assistant Professor, Department of Economic Sociology, Faculty of sociology, SaintPetersburg State University, Saint Petersburg, Russian Federation. Email: o.a.taranova@gmail.com

Junkai Jin - Post-graduate student, Department of Economic Sociology, Saint-Petersburg State University, Saint Petersburg, Russian Federation. Email: j530519513@126.com 
Blaakilde A.L., Nilsson G. (eds.) (2014) Nordic Seniors on the Move: Mobility and Migration in Later Life. Lund: Lund University.

Bourdieu P. (2004) Razlicheniye: sotsial'naya kritika suzhdeniya [Distinction: A Social Critique of the Judgement of Taste]. Zapadnaya ekonomicheskaya sotsiologiya: Khrestomatiya sovremennoy klassiki [Western Economic Sociology: Modern Classics Reader]. Moscow: Rossiyskaya politicheskaya entsiklopediya (ROSSPEN):537-565.

Gremchenko Y., Roshchina Y. (2016) Faktory sklonnosti k zdorovomu obrazu zhizni [Factors of a Propensity for a Healthy Lifestyle]. Vestnik Rossiyskogo monitoringa ekonomicheskogo polozheniya i zdorov'ya naseleniya NIU VSHE (RLMS-HSE) [Bulletin of the Russian Monitoring of the Economic Situation and Public Health of the Higher School of Economics], (6): 118-163.

Lévi-Strauss C. (2008) The Culinary Triangle. In: C. Counihan, P. Van Esterik (eds.) Food and Culture: A Reader. New York: Routledge: 36-43.

Kolosnitsyna M., Berdnikova A. (2009) Izbytochnyy ves: skol'ko eto stoit i chto s etim delat'? [Obesity: How Much Does it Cost and What to Do?] Prikladnaya ekonometrika [Applied Econometrics], (3-15): 72-92.

Kozyreva P., Safronova A., Starovoytov M. (2014) Analiz fakticheskogo pitaniya i pishchevogo statusa razlichnykh grupp naseleniya [Analysis of Actual Nutrition and Nutritional Status of Different Population Groups]. Vestnik Rossiyskogo monitoringa ekonomicheskogo polozheniya i zdorov'ya naseleniya NIU VSHE (RLMS-HSE) [Bulletin of the Russian Monitoring of the Economic Situation and Public Health of the Higher School of Economics (RLMS-HSE)], (4): 131-166.

Petrostat (2015) Potreblenie produktov pitaniya v domashnikh khozyaystvakh Sankt-Peterburga. [Food Consumption in Households of St. Petersburg]. Avaible at: http://petrostat.gks.ru/wps/wcm/ connect/rosstat_ts/petrostat/resources/0fd259004eb7121ebacefb0d534aab22/15000516-2015.pdf (accessed 1 October 2017).

Petrostat (2013) Itogi vyborochnogo nablyudeniya ratsiona pitaniya naseleniya v 2013 godu. [Results of Selective Observation of the Diet of the Population in 2013]. Avaible at: http://petrostat.gks. $\mathrm{ru} / \mathrm{wps} / \mathrm{wcm} /$ connect/rosstat_ts/petrostat/resources/627571804eaa60daa971fb0d534aab22.pdf (accessed 1 October 2017).

Richards A. (1995) Land, Labour, and Diet in Northern Rhodesia: An Economic Study of the Bemba Tribe. Munster: LIT Verlag.

Rosstat (2016) Ratsion pitaniya naseleniya 2013. [Population Diet in 2013]. Available at: http:// www.gks.ru/free_doc/new_site/population/urov/razion.pdf (accessed 1 October 2017).

Veselov Y. (2015) Povsednevnyye praktiki pitaniya [Everyday Nutrition Practices]. Sotsiologicheskiye issledovaniya [Sociological Research], (1): 95-104.

Veselov Y. (2014) Sotsiologiya pitaniya: teoreticheskiye osnovaniya [Sociology of Nutrition: Theoretical Foundations]. Problemy teoreticheskoy sotsiologii [Problems of Theoretical Sociology], (10): 168-199.

Veselov Y., Jin J. (2017) Sankt-Peterburg v zerkale sravnitel'noy sotsiologii pitaniya [Saint-Petersburg in the Mirror of the Sociology of Food]. Ekonomicheskaya kul'tura megapolisa. Al'manakh Tsentra issledovaniy ekonomicheskoy kul'tury [The Economic Culture of a Megalopolis. Almanac of The Economic Culture Studies Center]. SPb: Institut Gaydara:248-268.

Weber M. (1990) Izbrannyye proizvedeniya [Selected Writings]. Moscow: Progress.

WHO (2017) 10 vedushchih prichin smerti v mire [10 Leading Causes of Death in the World]. Available at: http://www.who.int/mediacentre/factsheets/fs310/en/ (accessed 1 October 2017). WHO (2016) Nepolnotsennoye pitaniye $v$ tsentre vnimaniya. [Inadequate Nutrition in the Focus of Attention]. Available at: http://www.who.int/nutrition/pressrelease-FAOWHO-symposium-malnutrition/ru/ (accessed 1 October 2017).

Zarubina N. (2014) Praktiki pitaniya kak marker i faktor sotsial'nogo neravenstva v Rossii [Nutrition Practices as a Marker and a Factor of Social Inequality in Russia]. Istoricheskaya psikhologiya i sotsiologiya istorii [Historical Psychology and Sociology of History], (2): 46-62.

Zarubina N., Kravchenko S. (eds.) (2017) Sotsiologiya pitaniya: traditsii i transformatsii [Sociology of Nutrition: Traditions and Transformations]. Moscow: MGIMO. 